\title{
OSTROWSKI AND TRAPEZOID TYPE INEQUALITIES RELATED TO POMPEIU'S MEAN VALUE THEOREM
}

\author{
Pietro Cerone, Sever S. Dragomir and Eder Kikianty
}

Abstract. In this paper, some new Ostrowski and trapezoid type inequalities, which are related to Pompeiu's mean value theorem, are obtained for absolutely continuous functions. Some applications to special means and inequalities for $f$-divergence measures are also given.

Mathematics subject classification (2010): Primary: 26D10, 26D15; Secondary: 26E60, 94A17.

Keywords and phrases: Pompeiu's mean value theorem, Ostrowski inequality, trapezoid inequality, special means, divergence measure.

\section{REFERENCES}

[1] A. M. Acu And F. D. Sofonea, On an inequality of Ostrowski type, J. Sci. Arts, No. 3 (16) (2011), 281-287.

[2] A. M. ACU, A. Baboş AND F. D. SofoneA, The mean value theorems and inequalities of Ostrowski type, Sci. Stud. Res. Ser. Math. Inform., 21, No. 1 (2011), 5-16.

[3] S. M. Ali And S. D. Silvey, A general class of coefficients of divergence of one distribution from another, J. Roy. Statist. Soc. Sec B, 28 (1966), 131-142.

[4] M. BETH BASSAT, $f$-entropies, probability of error and feature selection, Inform. Control, 39 (1978), 227-242.

[5] I. BURBEA AND C. R. RAO, On the convexity of some divergence measures based on entropy function, IEEE Trans. Inf. Th., 28, No. 3 (1982), 489-495.

[6] P. Cerone, On relationships between Ostrowski, trapezoidal and Chebychev identities and inequalities, Soochow J. Math., 28, No. 3 (2002), 311-328.

[7] P. CERONE, AND S. S. DRAGOMIR, Trapezoidal-type rules from an inequalities point of view, Handbook of analytic-computational methods in applied mathematics, Chapman \& Hall/CRC, Boca Raton, FL, 2000, 65-134.

[8] C. H. Chen, Statistical Pattern Recognition, Rocelle Park, New York, Hoyderc Book Co., 1973.

[9] C. K. CHOW AND C. N. LIN, Approximating discrete probability distributions with dependence trees, IEEE Trans. Inf. Th., 14, No. 3 (1968), 462-467.

[10] I. CSISZÁR, Information-type measures of difference of probability distributions and indirect observations, Studia Sci. Math. Hungar., 2 (1967), 299-318.

[11] I. CSISZÁr, On topological properties of $f$-divergences, Studia Sci. Math. Hungar., 2 (1967), 329339.

[12] I. Csiszár, AND J. KÖRner, Information Theory: Coding Theorem for Discrete Memoryless Systems, Academic Press, New York, 1981.

[13] S. S. Dragomir, An inequality of Ostrowski type via Pompeiu's mean value theorem, J. Inequal. Pure Appl. Math., 6, No. 3 (2005), Article 83, 9 pp.

[14] S. S. DRAGOMIR, Another Ostrowski type inequality via Pompeiu's mean value theorem, RGMIA Res. Rep. Coll., 16, No. 64 (2013), online: http://rgmia.org/papers/v16/v16a64.pdf.

[15] S. S. DRAGOMIR, Inequalities of Pompeiu's type for absolutely continuous functions with applications to Ostrowski's inequality, RGMIA Res. Rep. Coll., 16, No. 66 (2013), online: http://rgmia.org/ papers/v16/v16a66.pdf.

[16] D. V. Gokhale And S. Kullback, Information in Contingency Tables, New York, Marcel Decker, 1978. 
[17] J. H. HAVRDA AND F. CHARVAT, Quantification method classification process: concept of structural $\alpha$-entropy, Kybernetika, 3 (1967), 30-35.

[18] H. JefFReYs, An invariant form for the prior probability in estimating problems, Proc. Roy. Soc. London. Ser. A., 186 (1946), 453-461.

[19] T. T. KADOTA AND L. A. SHEPP, On the best finite set of linear observables for discriminating two Gaussian signals, IEEE Trans. Inf. Th., 13 (1967), 288-294.

[20] T. KAILATH, The divergence and Bhattacharyya distance measures in signal selection, IEEE Trans. Comm. Technology Vol COM-15 (1967), 52-60.

[21] J. N. KAPUR, A comparative assessment of various measures of directed divergence, Advances Manag. Stud., 3 (1984), 1-16.

[22] D. KAZAKos AND T. Cotsidas, A decision theory approach to the approximation of discrete probability densities, IEEE Trans. Perform. Anal. Machine Intell., 1 (1980), 61-67.

[23] S. Kullback And R. A. Leibler, On information and sufficiency, Annals Math. Statist., 22 (1951), 79-86.

[24] J. LIN, Divergence measures based on the Shannon entropy, IEEE Trans. Inf. Th., 37, No. 1 (1991), $145-151$.

[25] M. MEI, The theory of genetic distance and evaluation of human races, Jpn. J. Human Genet., 23 (1978), 341-369.

[26] A. OstrowsKI, Über die Absolutabweichung einer differentienbaren Funktionen von ihren Integralmittelwert, Comment. Math. Helv., 10 (1938), 226-227.

[27] J. PeČARIĆ And Š. Ungar, On an inequality of Ostrowski type, J. Ineq. Pure Appl. Math., 7, No. 4 (2006), Art. 151.

[28] J. PeČARIĆ And Š. Ungar, On the two-point Ostrowski inequality, Math. Inequal. Appl., 13, No. 2 (2010), 339-347.

[29] E. C. Pielou, Ecological Diversity, Wiley, New York, 1975.

[30] D. Pompeiu, Sur une proposition analogue au théorème des accroissements finis, Mathematica, Timişoara, 22 (1946), 143-146.

[31] E. C. PoPA, An inequality of Ostrowski type via a mean value theorem, Gen. Math., 15, No. 1 (2007), 93-100.

[32] C. R. RAO, Diversity and dissimilarity coefficients: a unified approach, Theor. Popul. Biol., 21 (1982), $24-43$.

[33] A. RÉnyi, On measures of entropy and information, Proc. Fourth Berkeley Symp. Math. Stat. and Prob., University of California Press, 1 (1961), 547-561.

[34] P. K. Sahoo And T. Riedel, Mean Value Theorems and Functional Equations, World Scientific, Singapore, New Jersey, London, Hong Kong, 2000.

[35] A. Sen, On Economic Inequality, Oxford University Press, London, 1973.

[36] B. D. Sharma AND D. P. MitTal, New non-additive measures of relative information, Journ. Comb. Inf. Sys. Sci., 2, No. 4 (1977), 122-132.

[37] H. SHIOYA AND T. DA-TE, A generalisation of Lin divergence and the derivative of a new information divergence, Elec. and Comm. in Japan, 78, No. 7 (1995), 37-40.

[38] I. J. TANEJA, Generalised Information Measures and their Applications, (http://www.mtm.ufsc.br/ taneja/bhtml/bhtml.html).

[39] F. TOPSOE, Some inequalities for information divergence and related measures of discrimination, Res. Rep. Coll. RGMIA, 2, No. 1 (1999), 85-98.

[40] H. THEIL, Economics and Information Theory, North-Holland, Amsterdam, 1967.

[41] H. TheIL, Statistical Decomposition Analysis, North-Holland, Amsterdam, 1972.

[42] I. VAJDA, Theory of Statistical Inference and Information, Dordrecht-Boston, Kluwer Academic Publishers, 1989. 